\title{
Nutritional status and predictors of weight loss in patients with systemic sclerosis
}

DOI:

10.1016/j.clnesp.2020.09.030

\section{Document Version}

Accepted author manuscript

Link to publication record in Manchester Research Explorer

\section{Citation for published version (APA):}

Hvas, C. L., Harrison, E., Eriksen, M. K., Herrick, A. L., Mclaughlin, J. T., \& Lal, S. (2020). Nutritional status and predictors of weight loss in patients with systemic sclerosis. Clinical Nutrition ESPEN. https://doi.org/10.1016/j.clnesp.2020.09.030

\section{Published in:}

Clinical Nutrition ESPEN

\section{Citing this paper}

Please note that where the full-text provided on Manchester Research Explorer is the Author Accepted Manuscript or Proof version this may differ from the final Published version. If citing, it is advised that you check and use the publisher's definitive version.

\section{General rights}

Copyright and moral rights for the publications made accessible in the Research Explorer are retained by the authors and/or other copyright owners and it is a condition of accessing publications that users recognise and abide by the legal requirements associated with these rights.

\section{Takedown policy}

If you believe that this document breaches copyright please refer to the University of Manchester's Takedown Procedures [http://man.ac.uk/04Y6Bo] or contact uml.scholarlycommunications@manchester.ac.uk providing relevant details, so we can investigate your claim.

\section{OPEN ACCESS}




\title{
Nutritional status and predictors of weight loss in patients with systemic sclerosis
}

Christian L. Hvas ${ }^{\mathrm{a},{ }^{*}}$, Elizabeth Harrison ${ }^{\mathrm{b}}$, Marcel K. Eriksen ${ }^{\mathrm{a}}$, Ariane L. Herrick ${ }^{\mathrm{c}}$, John T. McLaughlin $^{\mathrm{d}}$, Simon Lal ${ }^{\mathrm{d}, \mathrm{e}}$

${ }^{a}$ Department of Hepatology and Gastroenterology, Aarhus University Hospital, Aarhus, Denmark

${ }^{\mathrm{b}}$ Department of Gastroenterology, Shrewsbury and Telford Hospitals NHS Trust, Shrewsbury, United Kingdom

${ }^{\mathrm{c}}$ Division of Musculoskeletal and Dermatological Sciences, The University of Manchester, Salford Royal NHS Foundation Trust, Manchester Academic Health Science Centre, Manchester, UK M13 93

${ }^{\mathrm{d}}$ Division of Diabetes, Endocrinology and Gastroenterology, The University of Manchester, Salford Royal NHS Foundation Trust, Manchester Academic Health Science Centre, Manchester, UK M13 9NT

${ }^{\mathrm{e}}$ Intestinal Failure Unit, Salford Royal NHS Foundation Trust, Salford, United Kingdom

Running head: Malnutrition in systemic sclerosis

\section{*Corresponding author:}

Christian Lodberg Hvas, Department of Hepatology and Gastroenterology, Aarhus University Hospital, Palle Juul-Jensens Boulevard 99, DK-8200 Aarhus N, Denmark. Tel. +45 7845 3800. Fax +45 7845 3897. E-mail: christian.hvas@auh.rm.dk

ORCD ID 0000-0001-7973-7184

Word counts: Summary, 249; main text excluding references and Legends, 3,427.

\begin{abstract}
Abbreviations:
BIA, bioelectrical impedance analysis; BMI, body mass index; CRP, C-reactive protein; ESR, erythrocyte sedimentation rate; GI, gastro-intestinal; HAQ DI, health assessment questionnaire disability index; ICC, intraclass correlation coefficient; MAC, mid arm circumference; MAMC, mid-arm muscle circumference; MUAA, mid-upper arm anthropometry; MUST, malnutrition universal screening tool; PhA, phase angle; SHAQ, scleroderma health assessment questionnaire; SSC, systemic sclerosis; TSF, triceps skinfold thickness.
\end{abstract}




\section{ABSTRACT}

Background \& aims: Systemic sclerosis (SSc) commonly affects the gastrointestinal (GI) tract and predisposes to malnutrition. Few studies assessed body composition in outpatients with SSc or used more than one method for comparison over time. The aim of this study was to describe markers of nutrition and body composition in patients with SSc and to identify predictors of unintentional weight loss.

Methods: We consecutively included outpatients with SSc and performed a one-year followup. Gastrointestinal (GI) involvement was evaluated from clinical investigations. Patients completed questionnaires for organ involvement and functional status. Clinical assessment included body mass index (BMI), the malnutrition universal screening tool (MUST), interincisor distance, anthropometry, and bio-electrical impedance analysis (BIA).

Results: In total, 168 consecutive patients with SSc were included, and 127 (76\%) completed one-year follow-up. Thirteen (8\%) died before follow-up. Based on MUST scores, 12\% of patients were at high and $14 \%$ at medium risk of malnutrition. A low BMI was associated with small intestinal involvement $(\mathrm{p}<0.0001)$. Percentage body fat correlated with BMI, both when using four-site anthropometry $(r=0.65, \mathrm{p}<0.01)$ and BIA $(r=0.49, \mathrm{p}<0.01)$. Nine $(7 \%)$ patients had $>5 \%$ unintentional weight loss at follow-up. Independent baseline predictors of unintentional weight loss included upper GI involvement and disease severity estimated by Health Assessment Questionnaire Disability Index score.

Conclusions: Nutritional risk and GI involvement are frequent and closely correlated in patients with SSc. BIA and four-site anthropometry are comparable in the clinical assessment of patients with SSc. Unintentional weight loss is discrete and related to disease-specific characteristics.

Key words: systemic sclerosis; scleroderma; malnutrition; nutritional assessment; body composition. 


\section{INTRODUCTION}

Systemic sclerosis (SSc), or scleroderma, is a progressive fibrotic disease which affects multiple organ functions ${ }^{1}$. Malnutrition contributes to disease severity and is an important predictor of mortality in $\mathrm{SSc}^{2-4}$. Gastrointestinal symptoms are common in patients with SSc with the GI tract being a commonly affected organ ${ }^{5}$.

Malnutrition in patients with SSc may result from reduced appetite, dysphagia, early satiety, nausea, or malabsorption ${ }^{6}$. Using the malnutrition universal screening tool (MUST) ${ }^{7}$, malnutrition risk was evaluated in a Canadian registry-based cohort of 586 patients with SSc where $28 \%$ were found to be at medium or high risk of malnutrition ${ }^{6}$. Other groups that used MUST reported widely different proportions of patients, from $18 \%$ to $38 \%$, to be at medium or high risk of malnutrition ${ }^{8,9}$. In an Italian cohort of 160 patients with SSc, Caporali and coworkers defined malnutrition as a body mass index (BMI) $<20 \mathrm{~kg} / \mathrm{m}^{2}$ or a spontaneous weight loss of $\geq 10 \%$ and identified malnutrition in $15 \%{ }^{10}$.

Alternate measures of body composition may add to the use of BMI or MUST to estimate nutritional status and to predict weight loss. Few studies of patients with SSc investigated clinically applicable methods of body composition assessment. Although several authors assessed the usefulness of dual energy absorptiometry, this modality may have a limited role in the serial patient assessment in clinical practice ${ }^{11,12}$. Anthropometric measures may be applied, and one study found significantly lower measures of mid-upper arm anthropometry (MUAA) in 30 patients with SSc with gastrointestinal (GI) involvement compared with a group of healthy volunteers ${ }^{13}$. Two studies used bioimpedance analysis (BIA) or BIA-derived phase angle (PhA) which reflects cell membrane function and may be used as a surrogate marker of malnutrition. In the first study, Krause et al. reported the nutritional status of 124 patients with SSc and identified $34 \%$ to have 'bad nutritional status' and $22 \%$ to have 'insufficient nutritional status', based on $\mathrm{PhA}^{2}$. In the second study, BIA was compared to 
dual energy absorptiometry in 72 patients with SSc, demonstrating that BIA was valid to estimate fat free mass at group level, but noted deviations of up to $4.6 \mathrm{~kg}$ at individual level ${ }^{12}$. No other studies compared two clinically applicable body composition methods or repeated these measures over time.

Few clear risk factors for malnutrition or progressive weight loss have been identified in SSc. While correlations between malnutrition and clinical and paraclinical parameters have been demonstrated in cross-sectional studies ${ }^{8,10}$, changes of these measures over time and risk factors for deterioration are sparsely described.

In the present study, we aimed to describe the distribution of a panel of malnutrition risk factors and GI involvement in a well-defined cohort of patients with SSc and to investigate correlations between anthropometric measurements. We further investigated the occurrence of unintentional weight loss during follow-up and predictors of unintentional weight loss. 


\section{METHODS}

\section{Study design}

This was a single-centre prospective cohort study which was carried out in a rheumatology specialist centre in Salford, United Kingdom. We consecutively invited patients with SSc who attended the outpatient clinic for a pre-scheduled appointment during a 12-month enrolment period. Inclusion criteria were a confirmed diagnosis of SSc and age between 18 and 85 years. Exclusion criteria were a diagnosed eating disorder, a severe psychiatric illness, a non-SSc GI disease associated with weight loss, or acute illness.

Patients were assessed in the outpatient clinic upon inclusion. Follow-up assessments were planned for another scheduled clinic attendance after approximately one year (10 to 14 months). Because appointments were scheduled according to the patients' preferences and clinical need, study follow-up was not wholly confined to this period.

\section{Patient demographics and clinical assessment}

Demographic and clinical data were obtained from clinical records and patient interviews. Data included date of birth, gender, handedness, smoking status, current medications, GI investigations and diagnoses, SSc disease duration, severity and disease characteristics. Subtypes (limited cutaneous and diffuse cutaneous) were allocated according to the LeRoy criteria $^{14}$. SSc onset was defined by the first non-Raynaud's clinical manifestation. Available notes were searched for any record of relevant previous investigations (e.g. gastroscopy, pH and/or manometry studies, barium studies, cross-sectional imaging, breath tests for bacterial overgrowth, lung function tests, echocardiograms, electrocardiograms, etc.). Results of investigations were recorded. In addition, any GI diagnoses made prior to referral to the specialist centre were noted. Skin involvement was recorded using the Modified Rodnan Skin Score, which grades skin involvement between 0 (normal) and 3 (thickened, unable to pinch) 
at 17 different locations ${ }^{15}$. The severity of cardiac, respiratory and GI involvement was defined by the Medsger Scale, which uses organ-specific scales graded from 0 to 4 (normality to end-stage disease $)^{16}$. Maximum inter-incisor distance was measured using graduated callipers unless patients were missing their incisors or wore dentures.

\section{Patient-reported symptoms}

Patients completed questionnaires at inclusion and follow-up. University College of Los Angeles Scleroderma Clinical Trials Consortium (UCLA SCTC GIT) 2.0 symptom domain and total scores were recorded ${ }^{17,18}$. Patients also completed the Scleroderma Health Assessment Questionnaire (SHAQ) including the Health Assessment Questionnaire Disability Index (HAQ DI) and visual analogue scores ${ }^{19}$.

\section{Nutritional assessment}

Assessment was performed at inclusion and at follow-up. Height and weight were measured and used to calculate BMI. Any recalled recent (preceding 3 to 6 months) unintentional weight loss ( $<5 \%, 5$ to $10 \%$, or $>10 \%$ weight loss) was noted. At follow-up, percentage weight change was calculated. Patients with intentional weight loss on follow-up were excluded when seeking associations with clinical manifestations, but included when comparing methods of assessment.

Risk of malnutrition was calculated using the MUST tool ${ }^{7}$. For BMIs of 18.5 to $20 \mathrm{~kg} / \mathrm{m}^{2}$ patients scored 1 and for $<18.5 \mathrm{~kg} / \mathrm{m}^{2}$ scored 2 . For unplanned weight losses of 5 to $10 \%$ in the past 3 to 6 months, patients scored 1, and for $>10 \%$ loss scored 2. Because acutely ill patients were not included in this study, all patients had an acute disease effect score of zero. Patients with a total score of 0 had low risk of malnutrition, patients scoring 1 had medium risk, and patients scoring 2 or above had high risk. 


\section{Non-dominant mid-arm anthropometry}

Anthropometry measures body dimensions and allows the estimation of body composition. This study used non-dominant mid-arm anthropometry which is based on a two-component model of body composition (i.e. only fat mass or muscle mass). Measurements were made using standard anthropometric techniques ${ }^{20}$. Mid-arm circumference (MAC) was measured using a non-stretch tape measure with the patient standing. Triceps skinfold thickness (TSF), which is a double fold of skin and cutaneous tissue measured at the mid-point of the arm overlying the triceps muscle. The mid-arm muscle circumference (MAMC) was calculated from MAC and TSF. Measurements were compared to published age and gender centiles, which were based on 13,671 Americans aged 18 to 74 years $^{21}$.

\section{Four-site anthropometry}

The right-sided biceps, triceps, sub-scapular, and supra-iliac skinfolds were measured and used to calculate body density using the Durnin and Womersley equation ${ }^{20,22}$. Body density was then used to calculate percentage body fat using the two-component Siri equation ${ }^{23}$. This four-site anthropometry method of body composition assessment was introduced to the protocol during the study and was therefore not attempted in all patients.

\section{Bioelectrical impedance analysis (BIA)}

Percentage body fat and $\mathrm{PhA}$ were measured by bioelectrical impedance using a dual frequency (5kHz and 50kHz) Bodystat ${ }^{\circledR}$ 1500MDD (Bodystat Inc, Douglas, UK) analyser which uses a two-compartment body composition model ${ }^{24,25}$. Assessment was conducted according to the manufacturer's specifications, except that patients were studied in their normal state, i.e. no special preparation, such as fasting, was required. This was done to 
enable the assessment of BIA as a clinically applicable field method of body composition measurement. Patients with implanted electrical devices were excluded from BIA.

\section{Blood tests}

Routine plasma venous blood tests included albumin, C-reactive protein (CRP), erythrocyte sedimentation rate (ESR), magnesium and 25-OH-vitamin D2+D3 (vitamin D).

\section{Statistical analysis}

Descriptive statistics are reported as mean with standard deviation (SD). Comparisons of mean BMI, BIA, anthropometric percentage body fats, and weight changes were carried out using Student's t-test. Associations between MUST and demographic and clinical manifestations were sought using linear-by-linear analysis. Correlations (Pearson's (r) or Spearman's (s)) were sought between the baseline nutritional measures (e.g. BMI, weight, percentage body fat) and the changes and discrepancies in nutritional measures. Correlations between these and patient demographics, clinical manifestations, and symptoms were investigated using non-parametric regressions. Risk factors for the dichotomous outcome unintentional weight loss $>5 \%$ were identified using a multiple logistic regression analysis with a forward selection method. Agreement analyses were conducted between the measures of body composition. For all analyses, a p value of $<0.05$ was considered statistically significant. Data were analysed using Microsoft Excel, SPSS, and GraphPad Prism.

\section{Ethics statement}

The study complied with the declaration of Helsinki. All patients were included following their written informed consent. The study was approved by the North West Ethics Committee (12/NW/0247). 


\section{RESULTS}

\section{Patients demographics and GI involvement}

During the one-year inclusion period, we included 168 patients with SSc. Baseline patient characteristics are summarised in Table 1.

Gastro-oesophageal involvement had been evaluated using gastroscopy in 130 (77\%), barium swallow in 102 (61\%), cross-sectional thoracic imaging in 44 (26\%), and manometry in 15 (9\%). Together, 52\% patients had oesophageal dysmotility evidenced by either oesophageal dilatation and/or visualised abnormal motility. Acid suppression therapy was used by 144 (86\%).

Small bowel involvement had been evaluated using barium follow-through in 34 (20\%), cross-sectional abdominal imaging in 19 (11\%), and hydrogen breath test for small bowel bacterial overgrowth (SIBO) in 47 (34\%). Among the 47 patients who had hydrogen breath test, 25 (53\%) had a positive test indicative of SIBO, and 16 (64\%) required scheduled antibiotics for this condition. In total, 30 patients (18\%) had evidence of small intestinal involvement.

Investigations of colonic involvement included sigmoidoscopy, performed in 8\%, colonoscopy (22\%), computed tomography of colon (13\%), barium enema (3\%), and transit studies (1\%). Transit studies demonstrated severe constipation. Other investigations excluded alternative pathology. Regular or intermittent medications with an effect on colonic transit included laxatives (15\%), loperamide (5\%), and opiates (23\%).

\section{Nutritional status at inclusion}

Data to describe nutritional status at baseline are presented in Table 2. Of the 168 included patients, 43 (26\%) were at medium or high risk of malnutrition, using MUST criteria. Twelve (7\%) had a BMI $<18.5 \mathrm{~kg} / \mathrm{m}^{2}$. 
Correlations between BMI, MUST scores, and clinical manifestations were investigated.

The mean BMI did not differ between 88 patients with $\left(24.0 \pm 4.8 \mathrm{~kg} / \mathrm{m}^{2}\right)$ and 80 patients without $\left(25.2 \pm 5.0 \mathrm{~kg} / \mathrm{m}^{2}, \mathrm{~kg} / \mathrm{m}^{2}\right)$ oesophageal involvement ( $\left.\mathrm{p}=0.11\right)$. In contrast, the mean BMI was statistically significantly lower in 30 patients with (mean $22.0 \pm 3.9 \mathrm{~kg} / \mathrm{m}^{2}$ ) than in 138 patients without (mean $\left.25.1 \pm 4.9 \mathrm{~kg} / \mathrm{m}^{2}\right)$ small bowel involvement $(\mathrm{p}<0.01)$, and 13 (65\%) of 20 patients with high risk of malnutrition (MUST) had small intestinal involvement compared with 17 (14\%) of 125 of patients with low risk ( $<<0.01, \chi^{2}$ test). Baseline apertures were correlated and significantly linked to baseline BMIs ( $\mathrm{r}=0.191 ; \mathrm{p}=0.02)$ and MUSTs ( $\mathrm{s}=-$ $0.157 ; \mathrm{p}=0.05)$.

Four-site anthropometry and BIA were both used to estimate percentage body fat. Anthropometry was obtained in 98 patients. We found a statistically significant correlation between anthropometric percentage body fat and BMI ( $r=0.645 ; n=98 ; \mathrm{p}<0.01)$. Percentage body fat estimated by BIA was measured in 165 and also correlated closely with BMI $(r=0.491 ; n=165 ; p<0.01)$. PhA also correlated with anthropometric percentage body fat $(r=0.224 ; n=96 ; p=0.03)$. Total MUST scores correlated closely to anthropometric $(s=-0.479$; $\mathrm{n}=168 ; \mathrm{p}<0.01)$ and BIA ( $\mathrm{s}=-0.162 ; \mathrm{n}=165 ; \mathrm{p}=0.04)$ percentage body fats. Ninety-six patients had percentage body fats measured by both BIA and anthropometrics. Individuals' measures were closely correlated $(\mathrm{r}=0.683 ; \mathrm{p}<0.01)$. The mean discrepancy between individual patients' percentage body fat measures was $4.4 \pm 5.5 \%$. The intraclass correlation coefficient (ICC) was 0.51 (95\% limits of agreement (LoA) -15.1 to 6.4). Taken together, there was high collinearity between the two methods to measure percentage body fat, and they both correlated closely to nutritional risk.

Blood results are summarized in Table 2. When compared to reference ranges, plasma albumin was low in 1\% (2/163) and magnesium low in 7\% (8/111). C-reactive protein was elevated in 17\% (27/157) and erythrocyte sedimentation rate in 32\% (46/145). Vitamin D 
deficiency defined by a 25-OH-vitamin D2+3 below $50 \mathrm{nmol} / \mathrm{L}$ was present in $21 \%(32 / 155)$, and vitamin D insufficiency, i.e. values below $25 \mathrm{nmol} / \mathrm{L}$, was present in 34\% (52/155).

We found no correlations between self-reported HAQ and SHAQ responses and nutritional risk (data not shown).

\section{Changes in nutritional status during follow-up}

Follow-up was possible in 127 (76\%) of all patients and was carried out after median 14 (range 9 to 23) months. Loss to follow-up was not associated with any of the patient characteristics investigated (data not shown). Thirteen (8\%) patients died before follow-up, after a median of 9 months (range 1 to 20). Patients who died during follow-up had statistically significantly lower BMI at baseline than those who attended follow-up, i.e. mean $20.6 \pm 3.5 \mathrm{~kg} / \mathrm{m}^{2}$ vs. $24.9 \pm 4.9 \mathrm{~kg} / \mathrm{m}^{2}$ ( $\left.\mathrm{p}<0.01\right)$. One-year follow-up data are presented in Table 2.

In 69 (54\%) patients, body weight fluctuated by <3\% over 12 months. Seven (6\%) patients intentionally lost weight. Excluding these 7 patients, the mean unadjusted unintentional percentage weight change in the 120 remaining patients was $+0.51 \pm 6.5 \%$ (range $-11.0 \mathrm{~kg}$ to $+15.8 \mathrm{~kg}$ or $-17.5 \%$ to $+28.1 \%)$. In order to adjust for the varying follow-up period, weight changes were adjusted to represent 12 months, under the assumption that weight change trajectories were constant (Figure 1). The mean percentage unplanned weight change for 12 months was $+0.3 \pm 5.7 \%$ (range $-19.4 \%$ to $+21.4 \%$ ). Mean absolute changes in anthropometric measures were all minor and statistically insignificant, and they correlated closely to absolute changes in body weight (data not shown).

Serial anthropometric and BIA percentage body fats were available at follow-up for 66 patients. The mean anthropometric change in body fat was $+0.8 \pm 2.9$ (range -6.2 to +10.1 ) and the mean change in BIA body fat was $+1.2 \pm 2.5$ (range -4.6 to +8.2 ); there was a highly 
statistically significant correlation between changes in percentage body fat by the two

\section{Predictors of unintentional weight loss}

Percentage unintentional weight changes were correlated to demographics and disease severity, patient-reported symptoms, inter-incisor distance, and blood results from recruitment. Among baseline patient characteristics, only patient age reached statistical significance as a predictor of unintentional weight loss (Table 3). We observed no statistically significant differences in mean weight change with gender, disease sub-type, or anticentromere or anti-topoisomerase antibody status. When comparing unintentional weight changes with changes in patient-reported symptoms, we found statistically significant correlations with changes in gastro-oesophageal reflux, social functioning, and oral aperture (Table 4).

In order to identify risk factors for a clinically relevant weight loss, we applied multivariate logistic regression. Using a step-forward approach and investigating predictors of more than $5 \%$ unintentional weight loss, we identified upper GI involvement $(\mathrm{OR}=0.14$; $\mathrm{p}=0.03)$, HAQ DI score at baseline ( $\mathrm{OR}=3.45 ; \mathrm{p}=0.02)$, and difference in MAC (OR $=0.21$; $\mathrm{p}=0.0003$ ) after 12 months follow-up as independent and statistically significant risk factors (Table 5). 


\section{DISCUSSION}

This is the first study to evaluate the role of different modalities to measure body composition in a prospective cohort of patients with SSc with one-year follow-up data. We demonstrated that results obtained by four-site anthropometry, an accurate and readily available clinical method to evaluate body composition, and BIA are comparable in outpatients with SSc. Importantly, while a significant proportion of patients with SSc are at risk of malnutrition, those with upper GI involvement and severe disease estimated by the HAQ score are at particular risk of unintentional weight loss.

Malnutrition, indicated by a low BMI or a high MUST score, was frequent in the present cohort of patients with SSc. This confirms earlier findings, although only 7\% of patients in this study were underweight. While this frequency is lower than that reported by Baron et al. ${ }^{6}$ and higher than that found by Cereda et al. ${ }^{3}$, it is noteworthy that, in accordance with previous studies, almost $30 \%$ were overweight and $11 \%$ obese ${ }^{11,26}$.

Regarding body composition, measures of total body fat obtained by either BIA or anthropometry were highly correlated. One method was sufficient to estimate total body fat, and our data indicate that results obtained by BIA are comparable to those obtained by the more operator-dependant four-site anthropometry. This was seen despite BIA measures tending to be higher than measures obtained by anthropometry. Anthropometric measures may have been biased by cutaneous involvement, and potential BIA confounders include steroid use, altered hydration status, and presence of fibrosis. Second, BIA-derived PhA may be influenced by disease severity and nutritional status ${ }^{27}$. We found that both baseline and follow-up PhA showed a weaker correlation with BMI than either body fat measures and a weaker correlation with weight change. This indicates that PhA is not solely influenced by weight and suggests that substantial changes may be more indicative of severe disease. 
GI involvement is common in patients with SSc, and small bowel involvement was strongly associated with underweight. Oral involvement may, in theory, affect dietary choices and compromise oral intake. In this study, smaller baseline apertures were significantly linked to worse baseline BMIs and MUST scores. A link to worse baseline status is reported elsewhere $^{6}$. Oesophageal involvement causes dysphagia and reflux. Despite including many patients with oesophageal involvement, we found no associations between self-reported baseline UCLA reflux scores and BMI, MUST, or weight change. The absence of an association between self-reported symptoms and MUST score was reported previously ${ }^{6}$. Small intestinal involvement, which may cause abdominal distension and malabsorption, was associated with worse baseline BMI and MUST statuses. This is in accordance with previous findings ${ }^{6}$. We found no association between UCLA scores for diarrhoea or distension/bloating at baseline and BMI or MUST score. Also, changes in symptom scores and weight change did not correlate. Thus, the UCLA questionnaire may lack the sensitivity to fully detect those aspects of small intestinal involvement associated with nutritional risk. Despite small bowel involvement potentially causing malabsorption, clinicians should not rely on the ULCA questionnaire's small intestinal domains to identify patients at nutritional risk.

Predictors of unintentional weight loss in patients with SSc included high age and changes in social functioning, gastro-oesophageal reflux, and oral aperture. This is consistent with the finding in the multivariate analysis that upper GI involvement independently predicted unintentional weight loss. Other predictors such as baseline total HAQ score reflect disease severity, and changes in MAC over time may reflect loss of muscle mass. These findings may assist the clinician in identifying at-risk patients with SSc. Inter-incisor distance could be an easily performed and clinically relevant indirect predictor of unintentional weight loss, and repeated reflux assessments, not only based on a single UCLA reflux score, could prevent nutritional detriment from oesophageal involvement. The frequency of patients with an 
unintentional weight loss is in accordance with a recent registry data ${ }^{28}$, although GI involvement was not associated with weight loss in the registry study. Only few patients experienced unintentional weight loss at 12 months despite $26 \%$ being at risk of malnutrition. This is in accordance with previous findings that symptom changes over time are discrete ${ }^{29}$. The finding may not entirely reflect the clinical picture if loss to follow-up was related to nutritional risk. Also, a higher proportion of patients at high risk may have died, reflected by the lower baseline BMI in patients who died during follow-up. Causes of death were not recorded.

Important limitations apply to this study. Patients with acute disease were excluded, and patients who died before follow-up could not be evaluated. The follow-up period was short and may not have detected all risk factors. Our results may therefore underestimate the true prevalence of malnutrition. Further limitations result from the observational study design where some functional tests were only performed in symptomatic patients. Accordingly, pathology may solely reflect symptomatic patients, thereby underestimating the true prevalence of malnutrition-related organ pathology. The multivariate regression analysis aimed to rank the risk factors and identify independent risk drivers. The analysis therefore did not include multiple comparison correction.

In conclusion, this study confirms that a significant proportion of patients with SSc are at risk of malnutrition. Underweight is highly associated with small bowel involvement, but progressive weight loss is discrete and occurs in only a small proportion of patients. Individualised treatment may be optimised through disentangling the segmental GI pathology and analysis of body composition. Using either four-site anthropometry or BIA for assessment and monitoring and evaluating disease-specific markers such as oral aperture may aid day-to-day nutritional assessments. 


\section{ACKNOWLEDGEMENTS}

We appreciate the support of all patients who participated in the study.

\section{STATEMENT OF AUTHORSHIP}

$\mathrm{EH}$ collected the data pertaining to the patients with systemic sclerosis and performed initial data analysis. $\mathrm{CH}$ wrote the first manuscript draft. All authors took part in data analysis and writing and revising the paper. All authors approved the submitted version of the manuscript.

\section{DISCLOSURE STATEMENT}

EH was funded by the Raynaud's and Scleroderma Association. All other authors declare no conflicts of interest.

\section{FUNDING STATEMENT}

The Raynaud's and Scleroderma Association provided financial support. This work was supported by the NIHR Manchester Biomedical Research Centre. 


\section{TABLE AND FIGURE LEGENDS}

Table 1. Characteristics of 168 consecutive patients with systemic sclerosis who were included in this cohort study.

Table 2. Nutritional assessment of patients with systemic sclerosis at inclusion $(n=168)$ and at one-year follow-up ( $n=127)$.

Table 3. Statistical correlations between unintentional weight loss during one-year follow-up and baseline patient characteristics.

Table 4. Statistical correlations between unintentional weight loss during one-year follow-up and changes in symptoms or measures.

Table 5. Multiple logistic regression analysis for prediction of unintentional weight loss above $5 \%$ among patients with systemic sclerosis.

Figure 1. Percent weight change from inclusion to one-year follow-up. 


\section{References}

1. Denton CP, Khanna D. Systemic sclerosis. Lancet 2017;390:1685-99.

2. Krause L, Becker MO, Brueckner CS, Bellinghausen CJ, Becker C, Schneider U, et al. Nutritional status as marker for disease activity and severity predicting mortality in patients with systemic sclerosis. Ann Rheum Dis 2010;69:1951-7.

3. Cereda E, Codullo V, Klersy C, Breda S, Crippa A, Rava ML, et al. Disease-related nutritional risk and mortality in systemic sclerosis. Clin Nutr 2014;33:558-61.

4. Harrison E, Herrick AL, McLaughlin JT, Lal S. Malnutrition in systemic sclerosis. Rheumatology (Oxford) 2012;51:1747-56.

5. Alastal Y, Hammad TA, Renno A, Khalil B, Pierre J, Kwaah B, et al. Gastrointestinal manifestations associated with systemic sclerosis: results from the nationwide inpatient sample. Ann Gastroenterol 2017;30:498-503.

6. Baron M, Hudson M, Steele R. Malnutrition is common in systemic sclerosis: results from the Canadian scleroderma research group database. J Rheumatol 2009;36:2737-43.

7. Stratton RJ, Hackston A, Longmore D, Dixon R, Price S, Stroud M, et al. Malnutrition in hospital outpatients and inpatients: prevalence, concurrent validity and ease of use of the 'malnutrition universal screening tool' ('MUST') for adults. Br J Nutr 2004;92:799808.

8. Murtaugh MA, Frech TM. Nutritional status and gastrointestinal symptoms in systemic sclerosis patients. Clin Nutr 2013;32:130-5.

9. Ortiz-Santamaria V, Puig C, Soldevillla C, Barata A, Cuquet J, Recasens A. Nutritional support in patients with systemic sclerosis. Reumatol Clin 2014;10:283-7.

10. Caporali R, Caccialanza R, Bonino C, Klersy C, Cereda E, Xoxi B, et al. Disease-related malnutrition in outpatients with systemic sclerosis. Clin Nutr 2012;31:666-71. 
11. Marighela TF, Genaro Pde S, Pinheiro MM, Szejnfeld VL, Kayser C. Risk factors for body composition abnormalities in systemic sclerosis. Clin Rheumatol 2013;32:103744.

12. Spanjer MJ, Bultink IEM, de van der Schueren MAE, Voskuyl AE. Prevalence of malnutrition and validation of bioelectrical impedance analysis for the assessment of body composition in patients with systemic sclerosis. Rheumatology (Oxford) 2017;56:1008-12.

13. Lundberg AC, Akesson A, Akesson B. Dietary intake and nutritional status in patients with systemic sclerosis. Ann Rheum Dis 1992;51:1143-8.

14. LeRoy EC, Black C, Fleischmajer R, Jablonska S, Krieg T, Medsger TA, Jr., et al. Scleroderma (systemic sclerosis): classification, subsets and pathogenesis. $J$ Rheumatol 1988;15:202-5.

15. Clements PJ, Lachenbruch PA, Seibold JR, Zee B, Steen VD, Brennan P, et al. Skin thickness score in systemic sclerosis: an assessment of interobserver variability in 3 independent studies. J Rheumatol 1993;20:1892-6.

16. Medsger TA, Jr., Bombardieri S, Czirjak L, Scorza R, Della Rossa A, Bencivelli W. Assessment of disease severity and prognosis. Clin Exp Rheumatol 2003;21:S42-6.

17. Baron M, Hudson M, Steele R, Lo E. Validation of the UCLA Scleroderma Clinica Trial Gastrointestinal Tract Instrument version 2.0 for systemic sclerosis. J Rheumatol 2011;38:1925-30.

18. Khanna D, Hays RD, Maranian P, Seibold JR, Impens A, Mayes MD, et al. Reliability and validity of the University of California, Los Angeles Scleroderma Clinical Trial Consortium Gastrointestinal Tract Instrument. Arthritis Rheum 2009;61:1257-63. 
19. Steen VD, Medsger TA, Jr. The value of the Health Assessment Questionnaire and special patient-generated scales to demonstrate change in systemic sclerosis patients over time. Arthritis Rheum 1997;40:1984-91.

20. Lohman TG. Anthropometric standardization reference manual: Human Kinetics Press, 1988.

21. Bishop CW, Bowen PE, Ritchey SJ. Norms for nutritional assessment of American adults by upper arm anthropometry. Am J Clin Nutr 1981;34:2530-9.

22. Durnin JV, Womersley J. Body fat assessed from total body density and its estimation from skinfold thickness: measurements on 481 men and women aged from 16 to 72 years. Br J Nutr 1974;32:77-97.

23. Siri WE. The gross composition of the body. Adv Biol Med Phys 1956;4:239-80.

24. Hannan WJ, Cowen SJ, Plester CE, Fearon KC, deBeau A. Comparison of bio-impedance spectroscopy and multi-frequency bio-impedance analysis for the assessment of extracellular and total body water in surgical patients. Clin Sci (Lond) 1995;89:651-8.

25. Ghosh S, Meister D, Cowen S, Hannan WJ, Ferguson A. Body composition at the bedside. Eur J Gastroenterol Hepatol 1997;9:783-8.

26. Caramaschi P, Biasi D, Caimmi C, Barausse G, Gatti D, Ferrari M, et al. Relationship between body composition and both cardiovascular risk factors and lung function in systemic sclerosis. Clin Rheumatol 2014;33:77-82.

27. Stobaus N, Pirlich M, Valentini L, Schulzke JD, Norman K. Determinants of bioelectrical phase angle in disease. Br J Nutr 2012;107:1217-20.

28. Hughes M, Heal C, Siegert E, Hachulla E, Airó P, Riccardi A, et al. Significant weight loss in systemic sclerosis: a study from the EULAR Scleroderma Trials and Research (EUSTAR) database. Ann Rheum Dis 2020. 
29. Wilkens R, Frojk J, Olesen AB, Kannerup AS, Laurberg S, Krogh K. Slow progression of colorectal symptoms in patients with systemic sclerosis: an 8-year follow-up. Scand $J$ Rheumatol 2008;37:486-8. 

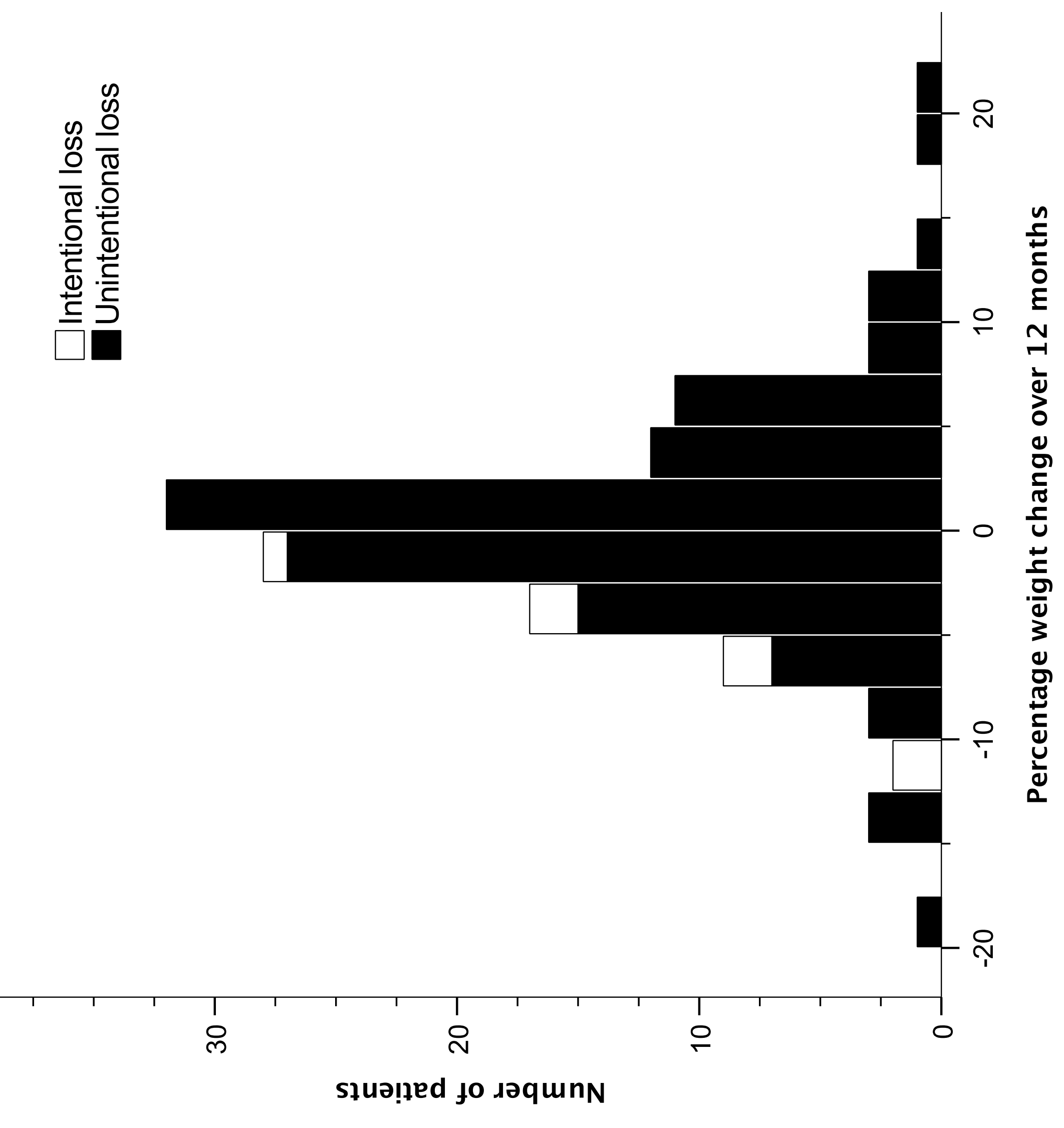

słuə!̣ed fo גəqunN

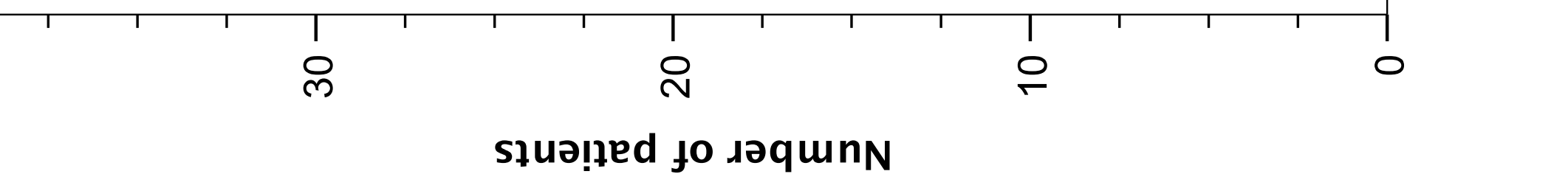

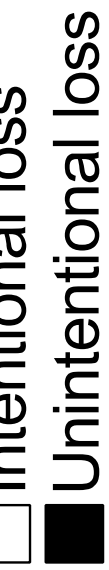

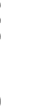

; 
Table 1. Characteristics of 168 consecutive patients with systemic sclerosis included in this cohort study.

\begin{tabular}{|c|c|}
\hline Characteristic & $\begin{array}{c}\text { All patients } \\
(n=168, \text { unless stated })\end{array}$ \\
\hline Age (years), median (range) & $61(25-81)$ \\
\hline Female, n (\%) & $137(81 \%)$ \\
\hline DcSSc, n (\%) & $45(27 \%)$ \\
\hline Anti-topoisomerase 1 antibody positive, $\mathrm{n}(\%)$ & $27(16 \%)$ \\
\hline Anti-centromere antibody positive, $\mathrm{n}(\%)$ & $57(34 \%)$ \\
\hline Time from onset of RP (months), median (range) & $167(0-778)$ \\
\hline Time from onset of SSc (months), median (range) & $133(0-742)$ \\
\hline HAQ DI score, mean \pm SD (range) $(n=165)$ & $1,4 \pm 0.8(0-3)$ \\
\hline $\begin{array}{l}\text { SHAQ visual analogue scores, mean } \pm \text { SD (range) }(n=166) \\
\text { Pain } \\
\text { GI } \\
\text { Lung } \\
\text { Vascular } \\
\text { Digital ulcers } \\
\text { Global disability }\end{array}$ & $\begin{array}{c}1.1 \pm 0.8(0-2.9) \\
0.9 \pm 0.9(0-3) \\
1.0 \pm 0.9(0-3) \\
1.1 \pm 0.9(0-3) \\
0.5 \pm 0.8(0-2.8) \\
1.3 \pm 0.8(0-3)\end{array}$ \\
\hline Medsger skin score (total), mean \pm SD (range) $(n=166)$ & $7 \pm 8(0-39)$ \\
\hline $\begin{array}{l}\text { Medsger gastrointestinal score, } \mathrm{n}(\%) \\
0: \text { Normal } \\
\text { 1: Mild } \\
\text { 2: Moderate } \\
\text { 3: Severe } \\
\text { 4: End-stage }\end{array}$ & $\begin{array}{c}79(47 \%) \\
67(40 \%) \\
12(7 \%) \\
3(2 \%) \\
7(4 \%)\end{array}$ \\
\hline $\begin{array}{l}\text { Medsger joint and tendon score, } \mathrm{n}(\%) \\
0: \text { Normal } \\
\text { 1: Mild } \\
\text { 2: Moderate } \\
\text { 3: Severe } \\
\text { 4: End-stage } \\
\text { Unknown }\end{array}$ & $\begin{aligned} & 99(59 \%) \\
& 5(3 \%) \\
& 20(12 \%) \\
& 12(7 \%) \\
& 8(5 \%) \\
& 24(14 \%)\end{aligned}$ \\
\hline $\begin{array}{l}\text { Medsger muscle score, } \mathrm{n}(\%) \\
0: \text { Normal } \\
\text { 1: Mild } \\
\text { 2: Moderate } \\
\text { 3: Severe } \\
\text { 4: End-stage } \\
\text { Unknown }\end{array}$ & $\begin{aligned} & 92(55 \%) \\
& 30(18 \%) \\
& 0(0 \%) \\
& 0(0 \%) \\
& 22(13 \%) \\
& 24(14 \%)\end{aligned}$ \\
\hline
\end{tabular}

Abbreviations: DcSSc, diffuse cutaneous systemic sclerosis; HAQ DI, Health Assessment Questionnaire Disability Index; RP, Raynaud's phenomenon; SHAQ, scleroderma HAQ. 
Table 2. Nutritional assessment of patients with systemic sclerosis at inclusion $(n=168)$ and at one-year follow-up ( $n=127)$.

\begin{tabular}{|c|c|c|}
\hline Nutritional Measure & $\begin{array}{c}\text { At inclusion } \\
(n=168, \text { unless stated })\end{array}$ & $\begin{array}{c}\text { At follow-up } \\
(n=127 \text {, unless stated })\end{array}$ \\
\hline $\begin{array}{l}\text { BMI }\left(\mathrm{kg} / \mathrm{m}^{2}\right), \text { mean (range) } \\
>30 \text { (obesity), } \mathrm{n}(\%) \\
>25-30 \text { (overweight), } \mathrm{n}(\%) \\
18.5-25, \mathrm{n}(\%) \\
\quad<18.5 \text { (underweight), } \mathrm{n}(\%)\end{array}$ & $\begin{array}{c}24.6(15.6-39.8) \\
19(11 \%) \\
50(30 \%) \\
87(52 \%) \\
12(7 \%)\end{array}$ & $\begin{array}{c}24.8(15.6-39.1) \\
17(13 \%) \\
37(29 \%) \\
63(50 \%) \\
10(8 \%)\end{array}$ \\
\hline $\begin{array}{l}\text { Unintentional weight loss } \\
>5 \%, \mathrm{n}(\%) \\
5-10 \%, \mathrm{n}(\%) \\
>10 \%, \mathrm{n}(\%)\end{array}$ & $\begin{array}{c}20(12 \%) \\
16(10 \%) \\
4(2 \%)\end{array}$ & $\begin{array}{l}9(7 \%) \\
6(5 \%) \\
3(2 \%)\end{array}$ \\
\hline $\begin{array}{l}\text { MUST } \\
\text { 0: Low, n (\%) } \\
\text { 1: Medium, n (\%) } \\
\geq 2 \text { : High, n (\%) }\end{array}$ & $\begin{array}{c}125(74 \%) \\
23(14 \%) \\
20(12 \%)\end{array}$ & $\begin{array}{c}101(80 \%) \\
13(10 \%) \\
13(10 \%)\end{array}$ \\
\hline $\mathrm{MAC} \leq 5^{\text {th }}$ centile, $\mathrm{n}(\%)$ & $\begin{array}{c}28(17 \%) \\
(n=168)\end{array}$ & $\begin{array}{l}18(14 \%) \\
(n=125)\end{array}$ \\
\hline TSF $\leq 5^{\text {th }}$ centile, $n(\%)$ & $\begin{array}{c}37(22 \%) \\
(n=167)\end{array}$ & $\begin{array}{c}20(16 \%) \\
(n=123)\end{array}$ \\
\hline MAMC $\leq 5^{\text {th }}$ centile, $n(\%)$ & $\begin{array}{c}16(10 \%) \\
(n=167)\end{array}$ & $\begin{array}{l}11(9 \%) \\
(n=123)\end{array}$ \\
\hline $\begin{array}{l}\text { Anthropometric percentage body fat, } \\
\text { mean } \pm \text { SD (range) }\end{array}$ & $\begin{array}{c}29.5 \pm 5.9(15-46) \\
(n=98)\end{array}$ & $\begin{array}{l}31.8 \pm 6.3(17-45) \\
(n=121)\end{array}$ \\
\hline $\begin{array}{l}\text { BIA percentage body fat, mean } \pm \text { SD } \\
\text { (range) }\end{array}$ & $\begin{array}{c}34.9 \pm 7.6 \%(11-52) \\
\quad(n=165)\end{array}$ & $\begin{array}{l}36.3 \pm 7.7 \%(12-57) \\
(n=122)\end{array}$ \\
\hline $\mathrm{PhA}$, mean $\pm \mathrm{SD}$ (range) & $\begin{array}{l}4.5 \pm 1.0(1.8-6.8) \\
\quad(n=165)\end{array}$ & $\begin{array}{c}4.6 \pm 0.9(1.8-6.6) \\
(n=122)\end{array}$ \\
\hline $\begin{array}{l}\text { Inter-incisor distance }(\mathrm{mm}) \text {, mean } \pm \\
\text { SD (range) }\end{array}$ & $\begin{array}{l}34 \pm 8(12-50) \\
(n=162)\end{array}$ & $\begin{array}{c}36 \pm 8(14-54) \\
(n=117)\end{array}$ \\
\hline
\end{tabular}

Baseline blood results, mean \pm SD

(range)

$\begin{array}{lcc}\text { Albumin }(\mathrm{g} / \mathrm{L}) & 43 \pm 3.5(31-50)(\mathrm{n}=163) & \mathrm{N} / \mathrm{A} \\ \text { Magnesium (mmol/L) } & 0.82 \pm 0.11(0.24-1.06)(\mathrm{m}=111) & \mathrm{N} / \mathrm{A} \\ \text { Vitamin D (nmol/L) } & 49 \pm 26.1(7.7-114.1)(\mathrm{n}=155) & \text { N/A } \\ \text { CRP (mg/L) } & 6.6 \pm 9.8(0-62)(\mathrm{m}=157) & \text { N/A } \\ \text { ESR (mm/hour) } & 18 \pm 16.8(\mathrm{n}=145) & \mathrm{N} / \mathrm{A}\end{array}$

Abbreviations: CRP, C-reactive protein; ESR, erythrocyte sedimentation rate; $\mathrm{PhA}$, phase angle; BIA, bioelectrical impedance analysis; BMI, body mass index; MAC, mid-arm circumference; MAMC, mid-arm muscle circumference; MUST, malnutrition universal screening tool; N/A, not available; TSF, triceps skinfold thickness. 
Table 3. Statistical correlations between unintentional weight loss during one-year follow-up and baseline characteristics at inclusion.

\begin{tabular}{|c|c|c|}
\hline Baseline data (n) & $\begin{array}{c}\text { Correlation } \\
(r=\text { Pearson; } s=S p e a r m a n)\end{array}$ & $\mathbf{P}$ \\
\hline \multicolumn{3}{|l|}{ Demographics } \\
\hline Age $(n=120)$ & $r=-0.216$ & 0.02 \\
\hline RP onset $(n=119)$ & $r=-0.020$ & 0.83 \\
\hline SSc onset $(n=120)$ & $r=-0.083$ & 0.37 \\
\hline \multicolumn{3}{|l|}{ Medsger disease severity } \\
\hline GI $(n=127)$ & $S=-0.037$ & 0.68 \\
\hline Lung (n=126) & $s=0.055$ & 0.68 \\
\hline Hearth $(n=125)$ & $S=-0.036$ & 0.69 \\
\hline HAQ DI score $(n=117)$ & $s=-0.018$ & 0.85 \\
\hline \multicolumn{3}{|l|}{ SHAQ visual analogue scores } \\
\hline Pain $(n=118)$ & $\mathrm{S}=0.028$ & 0.77 \\
\hline GI $(n=118)$ & $S=-0.033$ & 0.72 \\
\hline Lung ( $\mathrm{n}=117)$ & $S=-0.040$ & 0.67 \\
\hline Global disability $(n=118)$ & $S=-0.034$ & 0.72 \\
\hline \multicolumn{3}{|l|}{ UCLA domains } \\
\hline Reflux $(n=120)$ & $s=0.036$ & 0.70 \\
\hline Distension/bloating $(n=120)$ & $S=-0.040$ & 0.67 \\
\hline Soilage $(n=120)$ & $S=-0.007$ & 0.94 \\
\hline Diarrhoea $(n=120)$ & $S=-0.138$ & 0.13 \\
\hline Social functioning $(n=120)$ & $S=-0.126$ & 0.17 \\
\hline Emotional well-being $(n=120)$ & $S=-0.106$ & 0.25 \\
\hline Constipation $(n=120)$ & $\mathrm{S}=0.080$ & 0.39 \\
\hline Total GI $(n=120)$ & $S=-0.037$ & 0.69 \\
\hline \multicolumn{3}{|l|}{ Clinical Measures } \\
\hline Oral aperture $(n=115)$ & $S=-0.061$ & 0.52 \\
\hline \multicolumn{3}{|l|}{ Baseline blood results } \\
\hline Albumin $(n=119)$ & $r=0.280$ & 0.77 \\
\hline Magnesium ( $n=112)$ & $r=-0.061$ & 0.52 \\
\hline Un-supplemented vitamin $D(n=67)$ & $r=-0.002$ & 0.99 \\
\hline
\end{tabular}

Abbreviations: GI, gastrointestinal; HAQ, Health Assessment Questionnaire; DI, Disability Index; RP, Raynaud's phenomenon; SHAQ, Scleroderma HAQ; UCLA, University College of Los Angeles. 
Table 4. Statistical correlations between unintentional weight loss during one-year follow-up and changes in symptoms and measures.

\begin{tabular}{lcc}
\hline Baseline data $(n)$ & $\begin{array}{c}\text { Spearman's } \\
\text { correlation coefficient }\end{array}$ & P \\
\hline HAQ DI score $(n=120)$ & -0.009 & 0.92 \\
\hline SHAQ Visual Analogue Scores & & \\
Pain $(n=118)$ & 0.018 & 0.84 \\
GI $(n=118)$ & 0.037 & 0.69 \\
Lung ( $n=117)$ & -0.085 & 0.36 \\
Global disability $(n=118)$ & -0.069 & 0.46 \\
\hline UCLA domains & & \\
Reflux (n=120) & 0.195 & 0.03 \\
Distension/bloating $(n=120)$ & 0.048 & 0.60 \\
Soilage $(n=120)$ & 0.027 & 0.77 \\
Diarrhoea ( $n=120)$ & 0.012 & 0.90 \\
Social functioning $(n=119)$ & 0.212 & 0.02 \\
Emotional well-being $(n=120)$ & -0.107 & 0.25 \\
Constipation $(n=120)$ & -0.106 & 0.25 \\
Total GI $(n=119)$ & 0.790 & 0.39 \\
\hline Clinical Measures & & $<0.01$ \\
Oral aperture $(n=111)$ & 0.327 & \\
\hline
\end{tabular}

Abbreviations: GI, gastrointestinal; HAQ, Health Assessment Questionnaire; DI, Disability Index; RP, Raynaud's phenomenon; SHAQ, Scleroderma HAQ; UCLA, University College of Los Angeles. 
Table 5. Independent risk factors for unintentional weight loss above 5\% among patients with systemic sclerosis, identified by multivariate logistic regression analysis $\left(\mathrm{R}^{2}=0.42\right)$.

\begin{tabular}{lccc}
\hline Risk factor & OR & $95 \%$ Cl & P value \\
\hline Upper Gl involvement & 0.14 & $0.02-0.84$ & 0.0323 \\
\hline HAQ DI score, baseline & 3.45 & $1.36-10.49$ & 0.0155 \\
\hline MAC, difference after 12 months (cm) & 0.21 & $0.08-0.43$ & 0.0003 \\
\hline
\end{tabular}

Abbreviations: CI, confidence interval; GI, gastrointestinal; HAQ DI, Health Assessment Questionnaire Disability Index; MAC, mid arm circumference; OR, odds ratio 